\title{
Dialysance of Molecules of Different Size in Reused Kiil, Ab-Gambro, and Rhône-Poulenc Dialysers
}

\author{
P. KRAMER, D. MATTHAEI, J. G. GO, H. J. TÖNNIS, F. SCHELER
}

British Medical fournal, 1972, 2, 320-322

\section{Summary}

Dialysances of urea, creatinine, ethylenediamine tetraacetic acid, and ouabain were determined in three different flat-bed dialysers during three successive uses on 15 patients. There were no untoward reactions. A significant decrease in dialysing efficiency was observed only with the Ab-Gambro dialyser, in which the dialysance of the small molecules decreased more than that of the large. This is thought to result from blood deposits on the membrane surface inhibiting exchange.

\section{Introduction}

Clinicians are depressingly familiar with costs as a limiting factor in providing haemodialysis for patients with chronic renal failure, and a more economical use of materials and the time of personnel is essential. One way to economize is to reuse dialysers (Shaldon et al., 1964; Tchetchik et al., 1966; Pollard et al., 1967; Lavender et al., 1968; Bell and Figuerora, 1970; Evans and Lines, 1970), provided this does not decrease dialysance (Muir et al., 1971). The study reported here shows that reusing membranes in flat-bed dialysers does not affect the dialysance of large molecules but it may lower the rate of clearance of small molecules.

\section{Materials and Methods}

The dialysance of urea (molecular weight 60), creatinine (molecular weight 113), ${ }^{14} \mathrm{C}$-ethylenediamine tetra-acetic acid (EDTA) (molecular weight 288), and ${ }^{3} \mathrm{H}$-ouabain (molecular weight 585) were determined during three successive uses of the Kiil, Ab-Gambro, and Rhône-Poulenc-B flat-bed dialysers in 15 patients.

During haemodialysis the dialysers were held in a vertical position. Blood was propelled into the top by a constant-speed roller pump and the rate of flow was adjusted by the bubble flow method (Kramer et al., 1972) to $150 \mathrm{ml} / \mathrm{min}$. The pressure gradient from blood to rinsing fluid was maintained at 100 $\mathrm{mm} \mathrm{Hg}$. A single pass system with rinsing fluid degasing was used, and the dialysate flow was always countercurrent to the blood flow. At the start of haemodialysis the patients were given an intravenous dose of ${ }^{14} \mathrm{C}$-EDTA $17 \mu \mathrm{Ci}(1.4 \mathrm{mg})$ and ${ }^{3} \mathrm{H}$ ouabain $83 \mu \mathrm{Ci}(0.004 \mathrm{mg})$. Depending on the individual requirements of the patients, 25,000 to $35,000 \mathrm{IU}$ of heparin was infused into the blood inlet of the dialyser at a constant rate during the dialysis.

Blood samples at the inlet and the outlet of the dialyser and dialysate samples were taken after four hours of dialysis. Urea and creatinine concentration were measured in a two-channel autonanalyser, using a modification of the method of Marsh

\footnotetext{
University Hospital, Department of Internal Medicine, Division of Nephrology, Göttingen, Federal Republic of Germany

P. KRAMER, M.D., Research Assistant

D. MATTHÁEI, CAND.MED., Medical Student

J. G. GQ, CAND.MED., Medical Student

F. SCHELER, M.D., Professor and Head of the Division of Nephrology
}

et al. (1965) for creatinine and a modification of the method of Folin and Wu (1949) for urea. ${ }^{14} \mathrm{C}-E D T A$ and ${ }^{3} \mathrm{H}$-ouabain were measured in a liquid scintillation spectrometer with an absolute activity analyser, using a commercially available scintillation fluid, Instagel. To calculate dialysance the concentrations of the four test substances in the dialysate were taken as zero, since the estimated levels were too low for reliable measurement.

\section{PROCEDURE FOR REUSE}

At the end of dialysis as much blood as possible was returned to the patient, using a new combined wash-out and blow-out technique for the Ab-Gambro and the Rhone-Poulenc dialysers. This technique needs only $150 \mathrm{ml}$ of extra saline $(0.9 \%)$ infusion and reduces the blood loss in the Rhône-Poulenc to $3.65 \pm 1.21 \mathrm{ml}$ and in the Ab-Gambro to $6.86 \pm 1.94 \mathrm{ml}$. The Kiil was washed out with $700 \mathrm{ml}$ of normal saline. Blood loss by this technique was $3.48 \pm 1.21 \mathrm{ml}$ in the dialyser and $3.55 \mathrm{ml} \pm$ $0.93 \mathrm{ml}$ in the venous blood lines.

The blood and the rinsing fluid compartments were then immediately rinsed with tap-water (inflow pressure $70 \mathrm{~mm} \mathrm{Hg}$ ), the cleaning being intensified by intermittent clamping of the outflow lines causing abrupt changes of pressure and flow in the dialyser. The blood compartments were rinsed until the water turned clear. Rinsing for ten minutes was enough for the Kiil and the Rhône-Poulenc but up to $\mathbf{4 0}$ minutes was sometimes needed for the Ab-Gambro.

After tap-water rinsing the dialysers were filled with $10 \%$ formalin for resterilization and storage. Formalin solution was introduced into the blood compartment from the arterial end of the dialyser at a hydrostatic pressure af $100 \mathrm{~mm} \mathrm{Hg}$. Air was removed by tilting the arterial end lower than the venous end. The average storage time was $2 \cdot 4$ days.

Before further use the blood compartments were rinsed with $500 \mathrm{ml}$ of normal saline $(1-21$. of saline was needed for the Ab-Gambro). The blood compartments were then dialysed against tap-water at a minimum flow rate of $1,000 \mathrm{ml} / \mathrm{min}$ for 30 minutes. Before connecting the dialyser to the rinsing fluid line the blood compartment was flushed with saline and the evacuant tested for the presence of formaldehyde with Clinitest tablets (Pollard et al., 1967).

\section{Results}

None of the patients had any untoward reaction. There was a significant decrease in the dialysance of urea $(P<0.01)$, creatinine $(P<0.01)$, and EDTA $(P<0.01)$ with the AbGambro dialyser (Fig. 1), and this was more pronounced in the case of urea $(P<0.05)$ and creatinine $(P<0.01)$ with the third use. As well as a decrease in dialysance of urea, creatinine, and EDTA with the Ab-Gambro dialyser the blood loss was greatest owing to blood pooling and clotting on the surface of the membrane. The dialysance of ouabain with the Ab-Gambro dialyser remained unchanged during the three successive dialyses (Fig. 1).

The dialysance of urea, EDTA, and ouabain remained the same with each use of the Kiil dialyser, but a significant decrease in creatinine dialysance was observed in the second dialysis compared with the first $(P<0.01)$ but not in the third compared with the first $(P<0.07)$ (Fig. 2). 
The dialysance of the four test substances remained unchanged in all three uses of the Rhône-Poulenc dialyser. Comparison of Figs. 2 and 3 shows that the dialysance of the large molecule substances, EDTA and ouabain, was higher with the Kiil than with the Rhône-Poulenc.

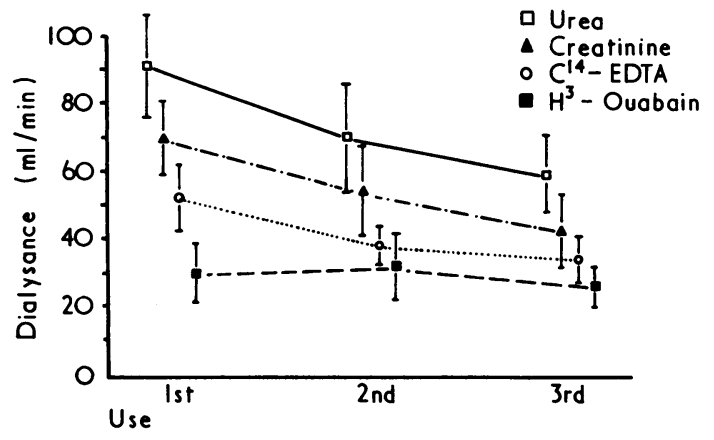

FIG. 1-Dialysance of urea, creatinine, EDTA, and ouabain in the AbGambro dialyser (rate of blood flow $150 \mathrm{ml} / \mathrm{min}$ ) at the first, second, and third use (mean values \pm S.D., $\mathbf{n}=15$ ).

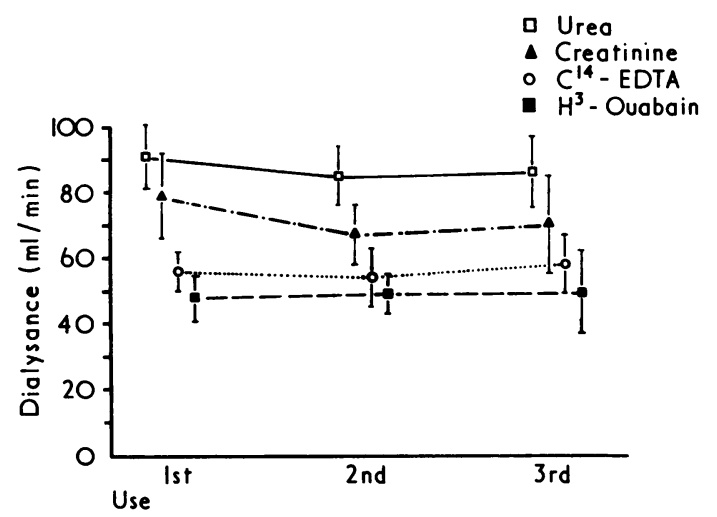

FIG. 2-Dialysance of urea, creatinine, EDTA, and ouabain in the Kiil dialyser (rate of blood flow $150 \mathrm{ml} / \mathrm{min}$ ) at the first, second, and third use (mean values \pm S.D., $\mathbf{n}=15$ )

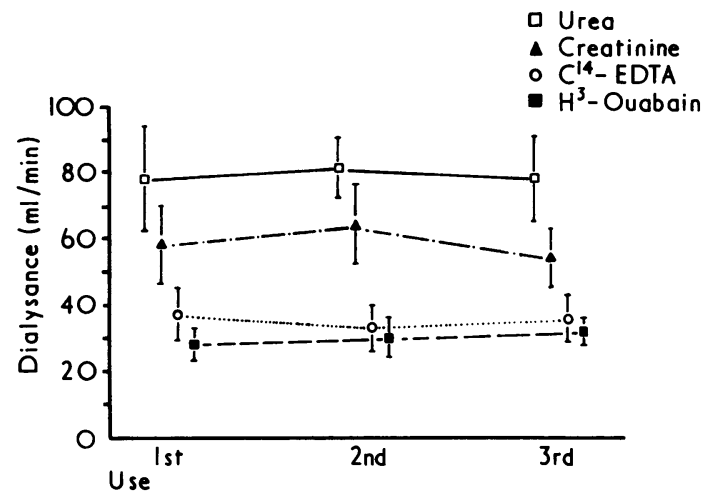
FIG. 3-Dialysance of urea, creatinine, EDTA, and ouabain in the Rhône-
Poulenc dialyser (rate of blood flow $150 \mathrm{ml} / \mathrm{min}$ ) at the first, second, and Poulenc dialyser (rate of blood flow 150
third use (mean values \pm S.D., $n=15$ ).

\section{Discussion}

The results show that the membranes of the Rhône-Poulenc and Ab-Gambro flat-bed dialysers may be reused. Reuse in the Rhône-Poulenc caused no decrease in the dialysance of urea, creatinine, and EDTA, and in this it was superior to the AbGambro. These findings contrast with those of Hartitzsch et al. (1971), who reported a $22 \%$ fall in urea and a $16 \%$ fall in creatinine dialysance in four out of six cases. This may be due to differences in wash-out and rinsing techniques or the dose of heparin. Unfortunately the authors did not give the details of their methods.

The dialysance of EDTA and ouabain was lower with the Rhône-Poulenc than with the Kiil dialyser, and also lower than with the first use of the Ab-Gambro. These findings are in part explained by the relatively small membrane surface area of the Rhône-Poulenc dialyser. According to the manufacturers, the thickness of the membrane in the Rhône-Poulenc and in the Kiil is the same. The lower dialysance of the larger molecules with the disposable dialysers may be due partly to the relatively low rate of blood flow. In multi-layer flat-bed dialysers such as the Rhone-Poulenc and the Ab-Gambro the cross-section of the blood stream is greater than in the two-layer Kiil and therefore the rate of blood flow is slower. This causes an uneven distribution of the flow in the blood compartments. As a result the slope of the urea and creatinine dialysance curve is steeper with the Rhône-Poulenc and Ab-Gambro dialysers than with the Kiil (Kramer et al., 1970, 1971). That is to say, an increase in the blood flow rate from 150 to $300 \mathrm{ml} / \mathrm{min}$ caused a greater increase in the urea and creatinine dialysance with the Rhône-Poulenc and $\mathrm{Ab}-\mathrm{Gambro}$ dialysers than with the Kiil. In our experience the blood flow rate for the two disposable dialysers in routine haemodialysis should be greater than $250 \mathrm{ml} / \mathrm{min}$. In these studies we kept to a rate of $150 \mathrm{ml} / \mathrm{min}$, since this could be maintained even with a badly positioned arterial canula.

The finding that the blood deposits on the surface of the membrane (Fig. 4) increased resistance to the transport of mainly the small molecules is most interesting. This could be explained in either of the following ways: (1) The deposits separate the molecules according to size, as does the Sephadex column, and

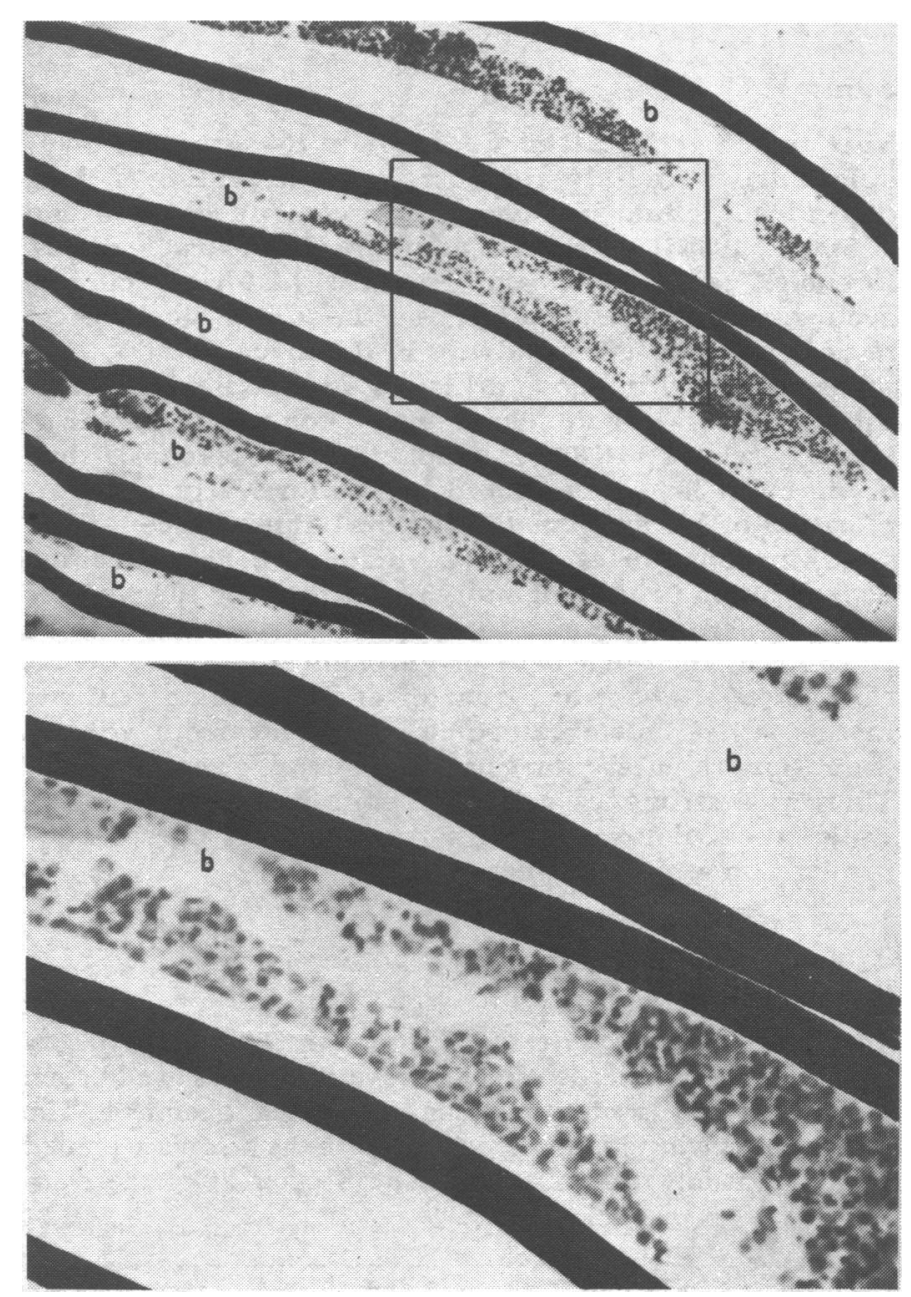

FIG. 4-Section of a coiled blood compartment (b) taken from an AbGambro dialyser after the third use. Blood deposits alternate with bare areas on the surface of the membrane (membrane touched up for purposes of reproduction). 
the passage of the smaller molecules is delayed because they enter the micropores of the material. (2) The deposits hinder exchange by acting like a porous sponge preventing close contact of the plasma with the membrane. This would limit the passage of only the small molecules since normally they are rapidly transported through the membrane and thus reduce the concentration gradient. This explanation would be consistent with the observation that the dialysance of small molecules is much more dependent on the rate of flow than is the dialysance of large molecules.

We wish to thank Dr. R. Kattermann, chief of the central laboratories, for the use of the autoanalyser, and especially $W$. S. Hüsken and his dialysis nursing staff for their expert help.

\section{References}

Bell, R. P., and Figueroa, J. E. (1970). British Medical fournal, 1, 788. Evans, D. B., and Lines, J. G. (1970). British Medical fournal, 1, 786.
Folin, T., and Wu, C. J. (1949). In Practical Physiological Chemistry, ed. P. B. Hawk, B. L. Oser, and W. H. Summerson, 12th edn., p. 506. New York, Blakiston.

Hartitzsch, B., Hoenich, N. A., and Kerr, D. N. S. (1971). Proceedings of the European Dialysis and Transplant Association, 8, 401.

Kramer, P., Quellhorst, E., Henning, H. V., and Scheler, F. (1970). In Aktuelle Probleme der Dialyserverfahren und der Niereninsuffizienz, III Symposion Innsbruck, 1969, ed. P. V. Dittrich and K. F. Kopp, p. 15. Friedberg Hessen, Bindernagel.

Kramer, P., Tönnis, H. J., Eichelberg, B., Kattermann, R., and Scheler, F. (1971). Proceedings of the European Dialysis and Transplant Association, 8,460 .

Kramer, P., Eichelberg, B., and Scheler, F. (1972). Medizinische Technik.

In press.
Lavender, A. R., Markley, F. W., and Forland, M. (1968). Proceedings of the European Dialysis and Transplant Association, 5,21 .

Marsh, W. H., Fingerhut, B., and Miller, H. (1965). Clinica, Chemistry,

11, 624. J. D. S. (1971). Proceedings of the European Dialysis and Transplant Association, 8, 445.

Pollard, T. L., Barnett, B. M. S., Eschbach, J. W., and Scribner, B. H. (1967). Transactions. American Society for Artificial Internal Organs, $13,24$.

Shaldon, S., Silva, H., and Rosen, S. M. (1964). British Medical fournal, 2,411 .

Tchetchik, M., Nakamoto, S., and Kolff, W. J. (1966). Fournal of the American Medical Association, 196, 451

$\$$

\title{
Amphetamine and Other Non-opioid Drug Users Attending a Special Drug Dependence Clinic
}

\author{
R. GARDNER, P. H. CONNELL
}

British Medical fournal, 1972, 2, 322-325

\section{Summary}

This paper reports the findings in 104 users of nonopioid drugs (mainly amphetamines) attending a drug dependence clinic in London between March 1968 and February 1969 in relation to demographic characteristics, forensic, psychiatric, and medical histories, clinical groups, management policy, and the use of biochemical tests for the presence of drugs in the urine.

Nearly one-third gave a history of starting amphetamine misuse while at school $(13.5 \%)$ or within a year of leaving school (16.3\%). Amphetamine psychosis had occurred in $35 \%$ of cases and was a more frequent complication of intravenous than of oral abuse. Except for a small proportion of older patients who have become dependent on drugs originally prescribed for therapeutic purposes, "maintenance therapy" is most unlikely to be effective in the treatment of amphetamine dependence. Nevertheless, about one-quarter of the younger patients in this series had obtained prescriptions from general practitioners after starting their drug abuse illicitly. There is a strong case for the compulsory notification under the Misuse of Drugs Act (1971) of persons dependent on amphetamines.

\section{Introduction}

The Dangerous Drugs Act (1967) provided for the compulsory notification of patients dependent on specified drugs of addiction and the setting up of special clinics for their treatment. The Regulations giving effect to the Act were in the first place limited to drugs (mainly opioids) covered by Section 11 of the Dan-

Drug Dependence Clinical Research and Treatment Unit, Bethlem Royal and Maudsley Hospitals, London

R. GARDNER, M.B., B.S., M.R.C.P., Senior Registrar

P. H. CONNELL, M.D., M.R.C.P., Physician gerous Drugs Act (1965), which seemed to present the most urgent and serious problem. Misuse of and dependence on other drugs have continued to be dealt with mainly by the general medical and psychiatric services.

From the outset the Bethlem Royal and Maudsley Hospitals jointly provided both outpatient and inpatient services for all forms of drug dependence (excluding alcohol, which was already dealt with in other facilities of the hospitals) in order that teaching and research could cover the total field (Connell, 1968d, 1970). An evening clinic for drug users, originally started in 1964 by one of us (P.H.C.), was reserved for non-opioid users-apart from intravenous users of amphetamines, who were seen at other times (Connell, 1968c).

The findings in opioid users attending the joint hospitals have been described elsewhere (Gardner and Connell, 1971), as has their initial management (Gardner and Connell, 1970). This paper is concerned with the demographic and clinical characteristics, patterns of drug misuse, and initial management of patients abusing non-opioid drugs (mainly amphetamines) who were seen during the first year of operation of the 1967 Act.

\section{Patients and Methods}

One hundred and four consecutive patients presenting with non-opioid drug abuse at this unit between 25 March 1968 and 28 February 1969 were studied. Data were obtained from various sources, and examination of the patient included the use of a standard questionnaire concerning drug usage (Connell and Gardner, unpublished) and full evaluation of the medical, drug, and psychiatric histories and physical and mental state. In 90 cases a specimen of urine was obtained on first attendance and was tested for amphetamines by a gas chromatographic method and for the barbiturate and opioid groups of drugs by thinlayer chromatography.

Data obtained from the patients' own statements, physical examination, urine examination, supporting data from G.P.s, probation officers, spouses, etc., and from finding the patient in possession of drug showed that 35 were intravenous methamphetamine users, 65 were amphetamine tablet users, three 